\title{
The association between generalized joint hypermobility and active horizontal shoulder abduction in 10-15 year old competitive swimmers
}

Tina Junge ${ }^{1,2,3^{*}}$, Peter Henriksen ${ }^{2,3}$, Heidi Lund Andersen ${ }^{1}$, Linette Dyg Byskov ${ }^{1}$, Hans Kromann Knudsen ${ }^{1}$ and Birgit Juul-Kristensen ${ }^{3,4}$

\begin{abstract}
Background: Increased shoulder mobility and Generalised Joint Hypermobility (GJH) are assumed to be predisposing risk factors for shoulder injuries. The association between GJH and shoulder mobility among competitive swimmers is unknown. The aim was to study the association between GJH and active horizontal shoulder abduction (AHSA) in young, competitive swimmers and to describe normative values of AHSA in this group.

Methods: In total, 92 swimmers (10-15 years) without shoulder pain participated. GJH was evaluated with the Beighton Tests (BT) for joint hypermobility. Shoulder mobility was measured as maximum AHSA. A multiple regression model was used to assess associations between GJH and AHSA.

Results: Overall, positive associations were found between GJH and AHSA. An increase of BT score was associated with an increase of AHSA, seen as an increased AHSA of $3.9^{\circ}, 5.7^{\circ}$ and $7.9^{\circ}$ by BT cut off points $\geq 5 / 9, \geq 6 / 9$ and $\geq 7 / 9$, respectively. Normative values for AHSA ranged from $40^{\circ}$ to $52^{\circ}$, depending on age.

Conclusions: Positive associations were found between GJH and AHSA, as maximum AHSA range increased with increasing BT scores. Due to lack of shoulder mobility tests in the BT scoring system, the AHSA test seems to be a promising supplemental test.
\end{abstract}

Keywords: Competitive swimmers, Generalized joint hypermobility, Active horizontal shoulder abduction, Shoulder injuries

\section{Background}

A competitive swimmer swims $9-110 \mathrm{~km}$ a week, depending on age, fitness level and training requirements [1]. This amount leads to a large amount of repetitive movements, which may result in overuse injuries of the shoulder [2]. Although competitive swimming attracts a large number of children and adolescents, there are almost no epidemiological studies on adolescent shoulder injuries for children or adolescents within this sport [3]. The prevalence of shoulder injuries in adult competitive

\footnotetext{
* Correspondence: tjunge@health.sdu.dk

'Department of Physiotherapy, University College Lillebaelt, Odense, Denmark

${ }^{2}$ Health Sciences Research Centre, University College Lillebaelt, Odense, Denmark

Full list of author information is available at the end of the article
}

swimmers varies from 40 to $91 \%$, partly due to inconsistency in definition of injury, study design and data collection methods [2].

Freestyle stroke is a whole body movement, but with the upper extremities producing $90 \%$ of the propulsive power [4], requiring shoulder strength, endurance and stability. Biomechanical challenges of the shoulder for the freestyle stroke may occur during the recovery phase, which demands a large Range Of Motion (ROM). A large ROM is anticipated to be advantageous by allowing the swimmer to achieve a body position that permits a larger stroke length, positively associated with swimming speed [2]. Consequently, the shoulder is repetitively forced into extension, horizontal abduction and internal rotation. Thus, swimming induces a large amount of stress on the 
anterior capsule and ligaments of the glenohumeral joint, which may lead to local shoulder laxity and/or an increased shoulder ROM $[2,5]$.

Increased shoulder ROM may be a genetic predisposition or an adaptation to the repetitive and excessive overhead movements in swimming. A condition in individuals with hereditary increased ROM is Generalised Joint Hypermobility (GJH), in which the ligaments and capsules are more lax compared with the normal population [6]. $\mathrm{GJH}$ is frequently present in swimmers, since as many as $20 \%$ of male and female adult swimmers are classified with GJH [7]. Also, a higher prevalence of GJH is found in young, competitive swimmers compared with non-competitive swimmers $[5,8]$. Increased shoulder ROM alone and GJH including shoulder hypermobility may play an important role in development of shoulder pain and injuries, and the extent of both conditions must be described as part of an injury sequence prevention strategy, focusing on underlying mechanisms [9].

$\mathrm{GJH}$ is most often assessed by the Beighton Tests (BT), involving a score from 0 to 9 , with a suggested cut off point for classification of $\mathrm{GJH}$ of $\geq 4 / 9$ in adults [10]. A cut off point for classifying children or adolescents with GJH has not been established, which is why the cut off point for GJH varies between studies [8, 11, 12]. The BT for hypermobility includes the 1st and 5th fingers, the elbows, the knees and forward bending, but there is no test for shoulder hypermobility [6]. The Active Horizontal Shoulder Abduction test (AHSA) (Illustration 1) could be a relevant shoulder mobility test for swimmers, simulating a swim-related stressful situation like the recovery phase of the freestyle stroke. Since the BT score is closely related to the general mobility of all joints [6] [13], the AHSA as supplemental test may provide a more comprehensive profile of the single swimmer's shoulder joint mobility.

In order to compare AHSA between different populations, normative data is required for young, competitive swimmers, taking into account age and sex. Such data exists for 15-21 year olds [14], however, no reference material covering younger swimmers between the ages of 10 to 15 years.

Thus, the aims of this study were to examine the association between shoulder ROM, defined by the Horizontal Shoulder Abduction test (AHSA) and the BT score, and to present normative values for AHSA in young, competitive swimmers between the ages of $10-15$ years.

\section{Methods}

\section{Participants}

In total, 116 young, competitive swimmers aged 1015 years were invited to take part in the current study, a substudy of the longitudinal cohort study, the "Physical Performance in Young Competitive Swimmers" (PPYCS).
PPYCS involves young, competitive swimmers from 5 different swim teams at Funen, Denmark. The overall purpose of PPYCS is to assess development of mobility, physical fitness, motor performance and sports-related injuries longitudinally, within this specific cohort.

The inclusion criteria were healthy swimmers aged 10-15 years, participating in competitive swim teams, defined as a swimmer taking part in competitions at a level corresponding to a local district, a larger region or at national level. Exclusion criteria were musculoskeletal pain, injury or illness preventing the swimmer from participating on the day of testing.

\section{Testers}

Testers were last semester physiotherapy students, who carried out this study as part of their final thesis. Prior to testing, the testers undertook a supervised training phase by two experienced physiotherapists (HKK \& TJ) in order to standardise test instructions and procedures and to approve a satisfactory inter- and intra tester reproducibility. The training phase included testing of approximately 100 adolescents aged $10-18$ years. For both the BT and the AHSA test, the testers gave instructions to the swimmers according to the standardized protocol, along with visual demonstrations. The testers performing the AHSA test were blinded to the status of the swimmers being GJH or controls. All swimmers were tested with the BT and afterwards with the AHSA test.

\section{Beighton tests (BT)}

$\mathrm{GJH}$ was evaluated according to the BT score $[6,15]$. The BT consists of five manoeuvres: 1 ) passive dorsiflexion of the little fingers beyond $90^{\circ}, 2$ ) passive apposition of the thumbs to the flexor aspects of the forearm, 3) hyperextension of the elbows beyond $10^{\circ}, 4$ ) hyperextension of the knees beyond $10^{\circ}$ and 5) forward flexion of the trunk with the knees straight, resting the palms easily on the floor. One point was allocated for each of the tests being positive as described, bilaterally for manoeuvres $1-4$, with a total score ranging from 0 to 9 [6]. The reliability of the Beighton score has been examined for the current test procedures in a corresponding age population with good to excellent inter and intra tester reproducibility [15]. Children were classified with GJH at different BT cut off points of $\geq 5 / 9, \geq 6 / 9$ and $\geq 7 / 9$. The control group included children with a BT score $\leq 4 / 9$.

\section{Test for active horizontal shoulder abduction (AHSA)}

AHSA was measured in prone using a Saunder Digital Inclinometer (Illustration 1). Each swimmer was lying in a prone starting position with the upper arm placed horizontally, $90^{\circ}$ elbow flexion, fingertips pointing towards the floor and the head turned in the opposite 


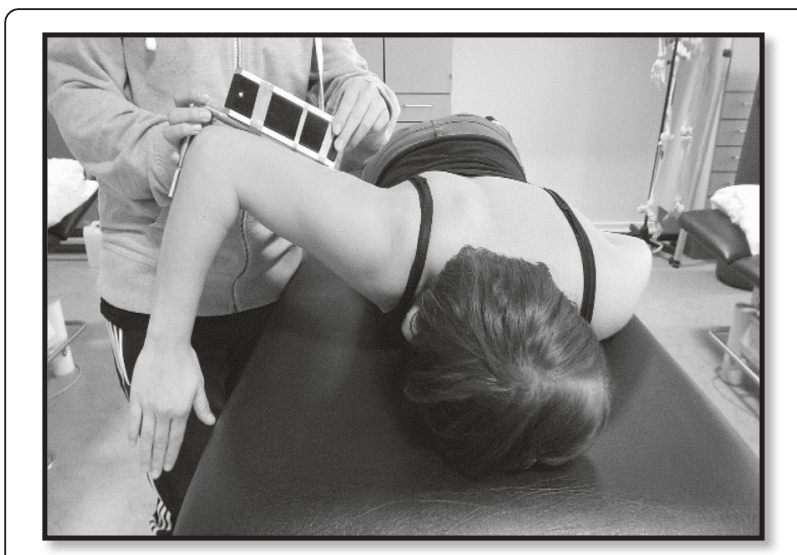

Illustration 1 Test of the horizontal shoulder abduction

direction of the shoulder being tested to avoid rotation of the spine. The Digital Inclinometer was mounted at the proximal end of an angle hinge, perpendicular to the distal end. The distal end was aligned to the forearm and the proximal to the upper arm, so that the elbow joint was kept in $90^{\circ}$ angle, to secure stabilization during measurements and to optimize standardization during measurements (Illustration 2). The swimmer was asked to lift the elbow as far as possible towards the ceiling. The test was performed three times actively for both shoulders, and the maximum angle of the upper arm in horizontal shoulder abduction was recorded in degrees.

\section{Data analysis}

Data was tested for Normality with Shapiro-Wilks tests. Since no significant difference was found between left and right shoulder in the AHSA test $(p=0.09)$, a mean of AHSA for both shoulders was used for further analyses. A multiple linear regression model was used to test the association between AHSA and the BT score, using the three different BT cut off points at $\geq 5 / 9, \geq 6 / 9$ and $\geq 7 / 9$, adjusted for sex and age.

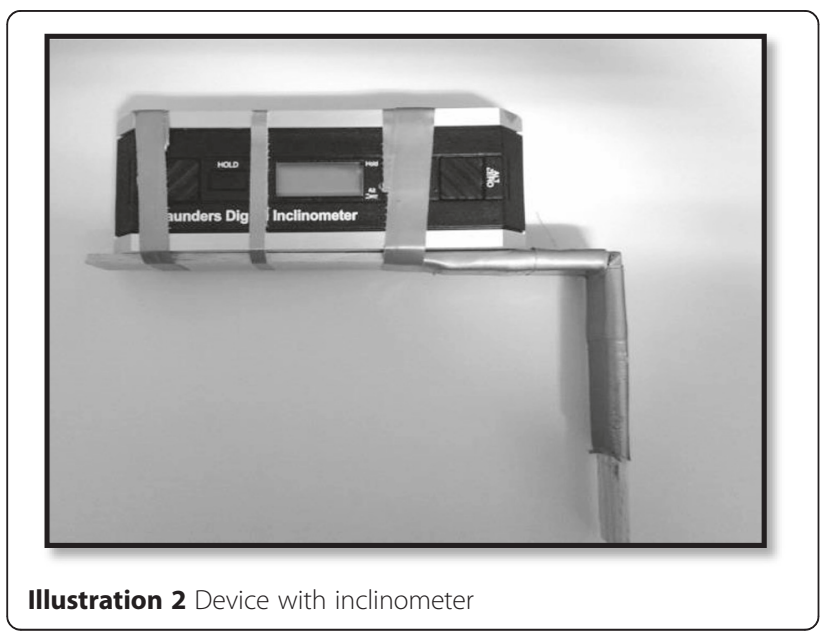

When calculating normative data of AHSA, age was found to be significantly or close to significant associated with the maximum AHSA for cut off point $\geq 6 / 9$ $(p=0.04)$ and $\geq 7 / 9(p=0.052)$, for which reason data were stratified by age. There was no statistically significant effect of sex on maximum AHSA, hence data for boys and girls were merged and presented for the entire sample.

A $p$-value of 0.05 or less was considered statistically significant. All statistical analyses were conducted in SPSS version 20 (IBM SPSS Inc, Chicago, IL, USA, 2012).

\section{Results}

In total, 92 young, competitive swimmers (mean age 13 years; 49 girls), with no shoulder pain participated.

In demographic variables, the only significant difference were height, with the GJH group being shorter (Table 1). A larger prevalence of girls was found in the GJH group, no matter the cut-off point (Tables 1 and 2).

Significant positive associations were found between the BT score and AHSA, adjusted for sex and age (Table 3). An increasing degree of AHSA was found with an increasing BT score for all cut-off points. Swimmers with BT at cut-off point $\geq 5 / 9$ had an AHSA which was $3.98^{\circ}$ higher than controls. For the BT score of $\geq 7 / 9$, the difference in AHSA increased to $7.90^{\circ}$ between groups. There was no effect of gender. A significant negative effect on maximum AHSA with age was only found at cut-off point $\geq 6 / 9$.

Normative data for the AHSA test were from $40.02^{\circ}$ to $51.83^{\circ}$ (mean $43.95^{\circ}$ ) across all age groups, for both controls and at all cut-off points for the GJH group, with the highest value and range of shoulder mobility for the youngest age groups, decreasing by age (Table 4 ).

\section{Discussion}

In the current study, a significant positive association was found between GJH and AHSA, with AHSA ranging from $5^{\circ}$ to $8^{\circ}$ higher than controls, with an increased BT

Table 1 Characteristics of participants with Generalised Joint Hypermobility (GJH), and without GJH (controls)

\begin{tabular}{llll}
\hline & $\begin{array}{l}\text { GJH }(n=29) \\
(\text { mean, SD) }\end{array}$ & $\begin{array}{l}\text { Controls }(n=63) \\
(\text { mean, SD) }\end{array}$ & p-value \\
\hline Sex (no. girls) & 20 & 29 & $0.04^{\mathrm{a}}$ \\
Age (years) & $12.62 \pm 1.6$ & $12.88 \pm 1.2$ & 0.37 \\
Height (m) & $1.61 \pm 11.7$ & $1.66 \pm 10.6$ & $0.05^{\mathrm{b}}$ \\
Mass (kg) & $50.01 \pm 11.7$ & $53.51 \pm 10.2$ & 0.14 \\
Right AHSA (degree) & $45.55 \pm 9.55$ & $43.23 \pm 13.6$ & 0.41 \\
Left AHSA (degree) & $44.06 \pm 9.68$ & $41.03 \pm 9.0$ & 0.14 \\
\hline
\end{tabular}

AHSA Active Horizontal Shoulder Abduction

${ }^{a}$ Significant difference between sexes

${ }^{b}$ Significant difference between groups 
Table 2 Prevalence stratified by sex for participants with Generalised Joint Hypermobility (GJH) at cut-off points 5/9, 6/9 and 7/9, and for controls

\begin{tabular}{|c|c|c|c|}
\hline & Participants (n) & GJH (\%) & Controls (\%) \\
\hline \multicolumn{4}{|c|}{ Cut off point $\geq 5 / 9$} \\
\hline Boys & 43 & $9(21)$ & $34(37)$ \\
\hline Girls & 49 & $20(41)$ & $29(31)$ \\
\hline Total & 92 & $29(32)$ & $63(68)$ \\
\hline \multicolumn{4}{|c|}{ Cut off point $\geq 6 / 9$} \\
\hline Boys & 43 & $5(12)$ & $38(41)$ \\
\hline Girls & 49 & $14(29)$ & $35(38)$ \\
\hline Total & 92 & $19(21)$ & $73(79)$ \\
\hline \multicolumn{4}{|c|}{ Cut off point $\geq 7 / 9$} \\
\hline Boys & 43 & $3(7)$ & $40(43.5)$ \\
\hline Girls & 49 & $9(18)$ & $40(43.5)$ \\
\hline Total & 92 & $12(13)$ & $80(87)$ \\
\hline
\end{tabular}

score. Normative data for AHSA ranged from $40^{\circ}$ to $52^{\circ}$, depending on age.

Swimmers with GJH $\geq 7 / 9$ presented with 15 and $20 \%$ higher maximum AHSA mobility than controls at the age of 10 and 14, respectively. These findings are in contrast to a previous study, where no association was found between GJH and shoulder rotation and extension in young swimmers, with only 4 swimmers classified as $\mathrm{GJH}$ at cut off point $\geq 5 / 9$ [16]. Likewise, in non sportspecific adults, there was no association between number of positive BT and passive glenohumeral ROM values $[17,18]$. The current data, however, indicates that maximum AHSA is associated with GJH in adolescent swimmers, and that this test may reveal increased shoulder mobility in this group.

Increased ROM of the shoulder is often seen in swimmers, and is generally considered a potential risk factor for shoulder pain and/or injuries. However, such relationship has not yet been confirmed [3, 19-21]. In a

Table 3 Association of Active Horizontal Shoulder Abduction in degrees and the Beighton tests score by cut off point $\geq 5 / 9, \geq 6$ / 9 and $\geq 7 / 9$

\begin{tabular}{llll}
\hline Beighton tests score & Estimate (degrees) & $95 \% \mathrm{Cl}$ & $p$-value \\
\hline Cut off point $\geq 5 / 9$ & 3.98 & {$[-0.12-8.07]$} & 0.057 \\
Age & -1.28 & {$[-2.66-0.10]$} & 0.069 \\
Girls & -2.22 & {$[-6.02-1.59]$} & 0.251 \\
Cut off point $\geq 6 / 9$ & 5.71 & {$[1.02-10.42]$} & $0.018^{\mathrm{a}}$ \\
Age & -1.43 & {$[-2.80-0.07]$} & $0.040^{\mathrm{a}}$ \\
Girls & -2.49 & {$[-6.27-1.29]$} & 0.194 \\
Cut off point $\geq 7 / 9$ & 7.90 & {$[2.27-13.52]$} & $0.007^{\mathrm{a}}$ \\
Age & -1.34 & {$[-2.69-0.01]$} & 0.052 \\
Girls & -2.44 & {$[-6.15-1.26]$} & 0.194 \\
\hline
\end{tabular}

${ }^{\mathrm{a}}$ Significant results, with $p \leq 0.05$
Table 4 Normative data for the Active Horizontal Shoulder Abduction (AHSA) test in degrees for both the GJH group at all cut off points and controls

\begin{tabular}{lll}
\hline Age & Mean \pm SD (degree) & $95 \% \mathrm{Cl}$ (degree) \\
\hline 10 & $51.83 \pm 10.05$ & $26.86-76.81$ \\
11 & $45.60 \pm 7.19$ & $41.62-49.58$ \\
12 & $40.71 \pm 10.22$ & $36.06-45.37$ \\
13 & $43.31 \pm 7.73$ & $39.79-46.83$ \\
14 & $40.02 \pm 8.11$ & $36.43-43.62$ \\
15 & $42.25 \pm 11.32$ & $34.15-50.35$ \\
\hline
\end{tabular}

cross-sectional study of 32 competitive swimmers aged 15 to 21 years, no association was seen between horizontal abduction and actual shoulder pain, however, classification of GJH was not included in the test battery [14]. Similarly, no association was found between shoulder internal and external ROM and the occurrence of pain in a cross-sectional study including15 participants, with six of these categorised as having shoulder laxity, but none with GJH [22]. The decreased passive stability in GJH along with a higher degree of AHSA requires a large contribution of active stability provided by the rotator cuff muscles to control for glenohumeral translation. Increased demands for active stability may hypothetically result in muscle fatigue, leading to repetitive micro trauma seen as overuse injuries.

At cut off point $\geq 7 / 9$, maximum AHSA was increased by $8^{\circ}$ compared to controls, and a question to be considered is whether GJH and increased shoulder ROM is predictive of shoulder injury and/or pain. The ability to establish a relationship between the BT score including maximum AHSA and shoulder injury in young competitive swimmers is limited by the cross-sectional design of the current study.

The current normative values are in line with a previous study of AHSA in 15-21 year old competitive swimmers [14], however, not tested with BT, but with AHSA presented for the whole group (left shoulder $44^{\circ} \pm 14^{\circ}$ and right shoulder $44^{\circ} \pm 16^{\circ}$ versus the current range of $\left.40-51^{\circ}\right)$. The current study included both swimmers with and without $\mathrm{GJH}$ in the normative values, representing a typical population of swimmers.

The prevalence of girls at 12 years (mean age) with GJH in the current population of swimmers was about twice as high as found in a normal population (different sports) at similar age; $41 \%$ vs. $20 \%, 29 \%$ vs. $15 \%$ and $18 \%$ vs. $5 \%$ for cut off points $\geq 5 / 9, \geq 6 / 9$ and $\geq 7 / 9$, respectively [8]. The same pattern was seen for the current 12 year old boys, with a prevalence of $\mathrm{GJH}$ also being about twice as high than the normal population of agematched boys being $19 \%$ vs. $9 \%, 10 \%$ vs. $6 \%$ and $5 \%$ vs. $1 \%$ for the three different cut off points, respectively [8]. However, the current high prevalence of GJH is in 
line with a previous study of adult, competitive swimmers, with prevalence of $20 \%$ for GJH $4 \geq / 9$ [7]. Contrary, a previous study of children participating in swimming, found girls aged 9 to have lower BT score than controls (median 2 vs. 3), with no group differences for girls aged 12, but with boys (aged 9 and 12) displaying higher BT score than controls (median 4 vs. 2, and median 2 vs. 1, respectively) [19]. The high prevalence of $\mathrm{GJH}$ in the current study of competitive swimmers may be due to the fact that large shoulder mobility with respect to stroke length is recognised as an advantage for competitive swimmer, thereby being seen more prevalent in this sport for those with GJH, as also previously reported [7].

The current study is in line with previous studies showing the prevalence of $\mathrm{GJH}$ increasing by age for girls and decreasing by age for boys $[8,23,24]$. Thus, the choice of cut off points for classification of GJH may vary from $\geq 4 / 9$ to $\geq 6 / 9$ within this age group $[8,11,12,25]$. With cut off point $\geq 6 / 9$ for $\mathrm{GJH}$, almost $33 \%$ of the current girls are considered to have GJH. This is recognised as a relatively high prevalence compared with a normal child population (mean age 13.8 years), where only $7 \%$ of the girls were classified GJH at this cut off point [25]. It seems difficult to determine a single cut off point for children and adolescents, since joint mobility represents a variable fluctuating condition during maturation [24]. It is therefore recommended that future studies present data of GJH prevalence with different cut off points, in addition to age and gender, as presented in the current study.

The limitations of the current study are mainly the unknown reliability and validity for the AHSA test. Previous studies found excellent reliability for inclinometer measurements of shoulder abduction ROM, when tested in a seated position [26]. The purpose of the current test was to measure shoulder mobility, expressed as AHSA, but as AHSA is a coupled motion performed actively, the outcome may rather indicate the swimmers ability to move the arm against gravity, than the actual and specific shoulder ROM. The concurrent validity of the current clinical AHSA test, therefore, remains unknown. However, AHSA was selected due to its similarity with the swimmers freestyle stroke movements, and as such AHSA represents the most swim-related shoulder mobility test.

Another limitation is, that the GJH group accounted for $2 / 3$ girls, which may hamper generalizability. However, since the prevalence of GJH among girls and women is higher in general, the current group may be well representative of the GJH group [27]. The normative values of the current study are distributed by age, but with the small sample sizes in the 10-year-old group (three subjects), the validity of this age group is hampered. A larger sample of this age group is therefore required in future studies for comparison to establish validity.

The strengths of this study are the standardized protocol of the BT and AHSA test, the supervised training phase of the testers and the large sample size. This study was carried out in young, competitive swimmers, making the results largely relevant for this group.

\section{Conclusions}

A positive association between AHSA and GJH was found in young, competitive swimmers, regardless of sex, age and cut off point. Normative values for AHSA ranged from $40^{\circ}$ to $52^{\circ}$, depending on age. Due to lack of shoulder mobility tests in the BT scoring system, the AHSA test seems to be a promising supplemental test, displaying shoulder mobility conditions more precisely.

Future longitudinal studies should test GJH including AHSA as predicting factors for shoulder injuries.

\section{Abbreviations}

AHSA, active horizontal shoulder abduction; BT, beighton tests; GJH, generalised joint hypermobility; PPYCS, physical performance in young competitive swimmers; ROM, range of motion

\section{Acknowledgements \\ The authors would like to thank physiotherapy students in PPYCS for their thorough assistance in testing the children.}

Funding

There was no funding for this study.

Availability of data and materials

At the time being the data will not be shared, as analyses and manuscripts are still being performed.

\section{Authors' contribution}

TJ and HKK contributed to the design of the study. TJ, HLA, LDB and HKK collected the data. TJ, HLA and LDB performed the data management. TJ, HLA and LDB performed the data analysis and TJ, HLA, LDB, PH, HKK and BJK were in charge of data interpretation. TJ, PH and BJK wrote the manuscript. All authors participated in data interpretation and contributed to manuscript revision. All authors read and approved the final version.

Competing interests

The authors declare that they have no competing interests.

\section{Consent for publication}

Not applicable.

\section{Ethics approval and consent to participate}

For the PPYCS study, The Regional Scientific Ethical Committee for Southern Denmark considered the protocol as non-invasive, since no intervention was performed in this study. Parents of each participating child received written information according to the Declaration of Helsinki, and before examination, each swimmer gave oral consent to participate in the study.

\section{Author details}

${ }^{1}$ Department of Physiotherapy, University College Lillebaelt, Odense, Denmark. ${ }^{2}$ Health Sciences Research Centre, University College Lillebaelt, Odense, Denmark. ${ }^{3}$ Department of Sports Science and Clinical Biomechanics, University of Southern Denmark, Odense, Denmark. ${ }^{4}$ Institute of Occupational Therapy, Physiotherapy and Radiography, Bergen University College, Bergen, Norway. 
Received: 18 March 2016 Accepted: 16 June 2016

Published online: 12 July 2016

\section{References}

1. Gaunt T, Maffulli N. Soothing suffering swimmers: a systematic review of the epidemiology, diagnosis, treatment and rehabilitation of musculoskeletal injuries in competitive swimmers. Br Med Bull. 2012;103(1):45-88.

2. Wanivenhaus F, Fox AJ, Chaudhury S, Rodeo SA. Epidemiology of injuries and prevention strategies in competitive swimmers. Sports health. 2012;4(3):246-51.

3. Kocher MS, Waters PM, Micheli $\amalg$. Upper extremity injuries in the paediatric athlete. Sports Med. 2000;30(2):117-35.

4. Heinlein SA, Cosgarea AJ. Biomechanical considerations in the competitive Swimmer's shoulder. Sports health. 2010;2(6):519-25.

5. Zemek MJ, Magee DJ. Comparison of glenohumeral joint laxity in elite and recreational swimmers. Clin J Sport Med. 1996;6(1):40-7.

6. Beighton P, Solomon L, Soskolne CL. Articular mobility in an African population. Ann Rheum Dis. 1973;32(5):413-8.

7. Pink MM, Tibone JE. The painful shoulder in the swimming athlete. Orthop Clin North Am. 2000:31(2):247-61.

8. Jansson A, Saartok T, Werner S, Renstrom P. General joint laxity in 1845 Swedish school children of different ages: age- and gender-specific distributions. Acta Paediatr. 2004:93(9):1202-6.

9. van Mechelen W, Hlobil H, Kemper HC. Incidence, severity, aetiology and prevention of sports injuries. A review of concepts. Sports Med. 1992; 14(2):82-99.

10. Grahame R, Bird HA, Child A. The revised (Brighton 1998) criteria for the diagnosis of benign joint hypermobility syndrome (BJHS). J Rheumatol. 2000;27(7):1777-9.

11. Juul-Kristensen B, Kristensen JH, Frausing B, Jensen DV, Rogind $H$, Remvig L. Motor competence and physical activity in 8-year-old school children with generalized joint hypermobility. Pediatrics. 2009;124(5):1380-7.

12. Clinch J, Deere K, Sayers A, Palmer S, Riddoch C, Tobias JH, Clark EM. Epidemiology of generalized joint laxity (hypermobility) in fourteen-year-old children from the UK: a population-based evaluation. Arthritis Rheum. 2011; 63(9):2819-27.

13. Bulbena A, Duro JC, Porta M, Faus S, Vallescar R, Martin-Santos R. Clinical assessment of hypermobility of joints: assembling criteria. J Rheumatol. 1992;19(1):115-22.

14. Beach ML, Whitney SL, Dickoff-Hoffman S. Relationship of shoulder flexibility, strength, and endurance to shoulder pain in competitive swimmers. J Orthop Sports Phys Ther. 1992;16(6):262-8.

15. Junge T, Jespersen E, Wedderkopp N, Juul-Kristensen B. Inter-tester reproducibility and inter-method agreement of two variations of the beighton test for determining generalised joint hypermobility in primary school children. BMC Pediatr. 2013;13:214

16. Baril B, Bivens B, Brown L, Travis J. The Effects of Generalized Joint Laxity and Shoulder Joint Laxity on Shoulder Joint ROM in Swimmers. In Proceedings of the Fourth Annual GRASP Symposium. Wichita, KS: Wichita State University; 2008. http://soar.wichita.edu/dspace/bitstream/10057/1333/ 1/grasp-2008-01.pdf. Accessed 15 Jan 2015.

17. Lintner SA, Levy A, Kenter K, Speer KP. Glenohumeral translation in the asymptomatic athlete's shoulder and its relationship to other clinically measurable anthropometric variables. Am J Sports Med. 1996;24(6):716-20.

18. Sauers EL, Borsa PA, Herling DE, Stanley RD. Instrumented measurement of glenohumeral joint laxity and its relationship to passive range of motion and generalized joint laxity. Am J Sports Med. 2001;29(2):143-50.

19. Jansson A, Saartok T, Werner S, Renstrom P. Evaluation of general joint laxity, shoulder laxity and mobility in competitive swimmers during growth and in normal controls. Scand J Med Sci Sports. 2005;15(3):169-76.

20. Warner JJ, Micheli LJ, Arslanian LE, Kennedy J, Kennedy R. Patterns of flexibility, laxity, and strength in normal shoulders and shoulders with instability and impingement. Am J Sports Med. 1990;18(4):366-75.

21. Hovis WD, Dean MT, Mallon WJ, Hawkins RJ. Posterior instability of the shoulder with secondary impingement in elite golfers. Am J Sports Med. 2002;30(6):886-90.

22. Bak K, Magnusson SP. Shoulder strength and range of motion in symptomatic and pain-free elite swimmers. Am J Sports Med. 1997;25(4):454-9.

23. Quatman CE, Ford KR, Myer GD, Paterno MV, Hewett TE. The effects of gender and pubertal status on generalized joint laxity in young athletes. Aust J Sci Med Sport. 2008;11(3):257-63.
24. Junge $T$, Larsen LR, Juul-Kristensen B, Wedderkopp $N$. The extent and risk of knee injuries in children aged 9-14 with Generalised Joint Hypermobility and knee joint hypermobility - the CHAMPS-study Denmark. BMC Musculoskelet Disord. 2015;16:143.

25. Tobias JH, Deere K, Palmer S, Clark EM, Clinch J. Joint hypermobility is a risk factor for musculoskeletal pain during adolescence: findings of a prospective cohort study. Arthritis Rheum. 2013;65(4):1107-15.

26. Kolber MJHW. The reliability and concurrent validity of shoulder mobility measurements using a digital inclinometer and goniometer: a technical report. Int J Sports Phys Ther. 2012;7(3):306-13.

27. Remvig L, Jensen DV, Ward RC. Epidemiology of general joint hypermobility and basis for the proposed criteria for benign joint hypermobility syndrome: review of the literature. J Rheumatol. 2007;34(4):804-9.

\section{Submit your next manuscript to BioMed Central and we will help you at every step:}

- We accept pre-submission inquiries

- Our selector tool helps you to find the most relevant journal

- We provide round the clock customer support

- Convenient online submission

- Thorough peer review

- Inclusion in PubMed and all major indexing services

- Maximum visibility for your research

Submit your manuscript at www.biomedcentral.com/submit
) Biomed Central 